\title{
Identifying the Effective Parameters in Soil Arching for Retaining Structure; A case study of Line 2 of Mashhad Subway
}

\author{
Mostafa Vahedian, Masoud cheraghi Seifabd ${ }^{\star 凶}$ and Alireza Baghbanan \\ Department of Mining Engineering, Isfahan University of Technology, Isfahan 84156-83111, Iran \\ Corresponding author’s Email: cheraghi@cc.iut.ac.ir; (DORCiD: 0000-0001-9460-6000
}

\begin{abstract}
The effective parameters on soil arching in retaining structures composed of the steel piles (2PIE300) and the steel anchors were considered using PLAXIS 3D TUNNEL for a three-dimensional numerical model. To better compare, it was assumed that external loading conditions and technical features of structural elements were the same. To determine the limits of effective parameters in fine (CL-ML) and coarse grains (SC-SM), according to the soil specifications of the stations A2 to L2 in in Mashhad urban railway line 2 (Iran), Hardening Soil Model (HS) was used. Modeling started with a horizontal and vertical distance of 2 meters and increased to a distance of 4 meters. The parameters of the soils including angles of internal friction, cohesion, density and elastic modulus and the distance between anchors have been selected to present the prediction model. All parameters of the soils have been used for multiple regression and artificial neural network modeling statistical analysis. To present a prediction model, 5 parameters including internal friction angles of soil, cohesion, soil density, distance between anchors and elastic modulus have been selected and all of them except final parameter have been used to analyze multiple regression and artificial neural network modeling. The results showed that the best regression model that could be presented is the correlation of $94 \%$ between measured and predicted values. The prediction effectiveness of the neural network model has been found to be acceptable as they produced higher correlation coefficient (99\%) between the variables and for the prediction of the factor of safety.
\end{abstract}

Keywords: Soil arching, Multiple regression, Artificial neural network, PLAXIS 3D TUNNEL, Line 2 of Mashhad urban railway, Excavation safety factor

\section{INTRODUCTION}

One of the most widely applied cases in engineering is estimating and predicting one parameter according to available parameters effective on it. In the last years, there has been an attempt in different engineering branches, to find the methods which would not require complex calculations and not be time-consuming. For this reason, various methods have been used in Geotechnical Engineering, such as Multivariate Regression Analysis (MRA) and the recent years, Artificial Neural Network (ANN).

Arching is one of phenomena repeatedly occurring in the field and laboratory. It has been found in underground structures such as underground canals. In underground tunnels, arching can be used to decrease the overburden pressure on structures. Redistribution of stresses due to arching effects can lead to changing the loads acting on the structure. These loads may be from the overburden pressure, surface loads and the lateral pressure of ground. Arching effect can be found in the natural excavation; has been used to describe the transfer stress phenomenon by mobilizing shear strength (Wang and Yen, 1974). In other words, aching is known as transferring stress from one failure mass to the next fix and stable masses (ASCE, 1958). Many investigations have been done in this field (Vermeer et al., 2001; Chen and Poulo, 2002; Kahyaoglu, 2009; Qiu-chang and Jian-wei, 2010; Kourkoulis et al., 2011). In the recent years, other researchers have investigated the subject (Fattah et al., 2015; Wu et al., 2017; Khosravi et al., 2018). Lai et al. (2020), for example, applied a total of 131 2D trapdoor-like discrete element models to address the soil arching effect, stress state and deformational behaviours of the piled embankments. The importance of the stabilization of soil or rock wall at the time of excavation has been considered by engineers. Accordingly, different methods of retaining structures have been considered as tools for the stabilization; these include concrete or steel piles, truss methods, cable anchorage method, and nailing in the soil. Soil arching is one of the properties of in the soil 
environments that can reduce the expenses of the project without reducing safety. This study considered soil arching phenomenon and the influencing parameters including density and angle of internal friction angle to calculate the factor of safety for a $10 \mathrm{~m}$ long definite retaining structure. The factor of safety has been obtained using the finite element code of PLAXIS 3D TUNNEL (Plaxis, 2004). Finally, this paper presents an equation to calculate the factor of safety from the influencing parameters of soil arching for design of a safe retaining structure with a minimum displacement.

\section{Using Neural Networks}

High speed computers and algorithms have made it possible to use the neural networks to solve complex industrial problems previously requiring many calculations (Hagan, 1996).

\section{Levenberg- Marquardt Algorithm}

In this research, the Levenberg-Marquardt algorithm was used to train the network. It is a kind of back propagation algorithm different from the Gaussian Newton's optimization algorithm. A new order of weights in the step of $k+1$ is calculated as follows (1):

$W(k+1)=w(k)-\left(J^{T} J+\lambda . I\right)^{-1} J^{T} . \varepsilon(k)$

$J$ is the Jacobian Matrix written for a Neuron as follows (2):

$$
J=\left[\begin{array}{ccc}
\frac{\partial \varepsilon_{1}}{\partial w_{1}} & \cdots & \frac{\partial \varepsilon_{1}}{\partial w_{n}} \\
\cdot & \cdots & \cdot \\
\cdot & \cdots & \cdot \\
\frac{\partial \varepsilon_{p}}{\partial w_{1}} & \cdots & \frac{\partial \varepsilon_{p}}{\partial w_{n}}
\end{array}\right]
$$

Where, $\lambda$ is a non-negative damping factor, $I$ is the identity matrix, $\mathrm{w}$ is the weight vector, and $\varepsilon$ is the error vector. There is difference between the output of network and the real output. Parameter $\lambda$ is corrected on the basis of the function of E. If $\mathrm{E}$ is deceased in any steps, it is accepted; otherwise, $\lambda$ will change and $w(k+1)$ will be calculated again.

\section{MATERIAL AND METHODS}

\footnotetext{
A case study: Line 2 project of Mashhad urban railway

Mashhad, the second largest religious city in the world, is located in the north-east of Iran. Tunnel of Mashhad Urban Railway line 2, with the length of $14 \mathrm{~km}$,
}

the excavation diameter of $9.43 \mathrm{~m}$ and the completed diameter of $8.4 \mathrm{~m}$, has been extended along the north-east to south-west, with 13 stations, named $\mathrm{A}_{2}$ to $\mathrm{L}_{2}$ (Figure. 1). This tunnel has been excavated by two TBM machines (EPB/Open) in two sides, one from the northern direction at the distance of $383 \mathrm{~m}$ from the station $\mathrm{A} 2$ and the other from the southern direction (Station L2).

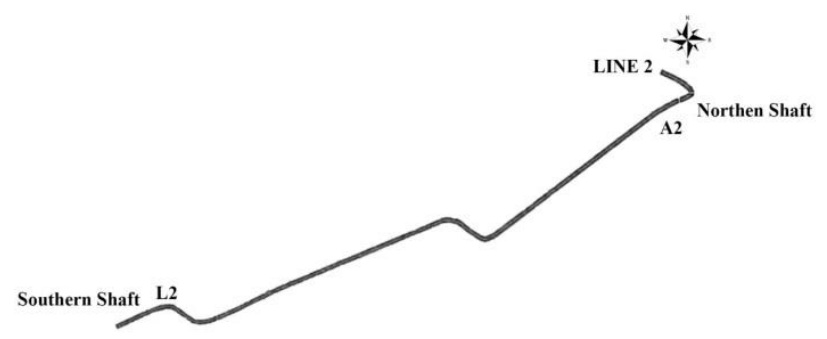

Figure 1. Mashhad Urban Railway line 2

By using the trial and error method, different dimensions related to the geometry of models, such as width of excavation, could be simulated and the desirable distance would be obtained for the model borders. Regarding the dimensions of the district for excavation and the above-mentioned subjects, the geometry of model is illustrated in two dimensions, as can be seen in Figure. 2. This geometry is the same for all models.

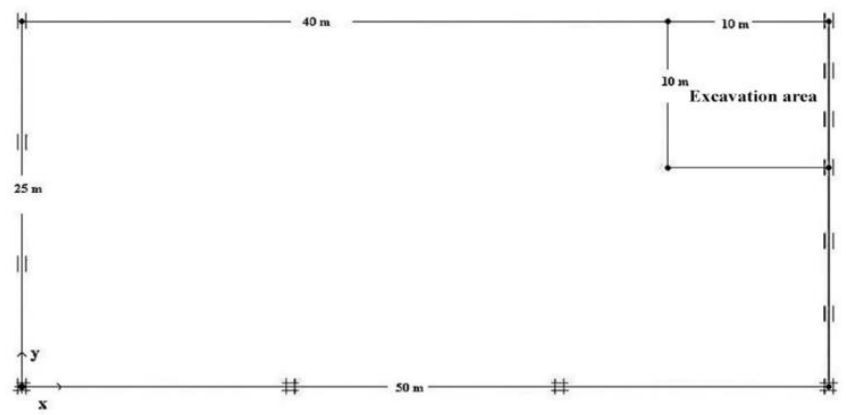

Figure 2. Dimensions of the model

\section{Soil material and proper behavioral model}

Soil of the station $\mathrm{A}_{2}$ is a fine grain one, while the soil of station $\mathrm{L}_{2}$ is a coarse one. According to this, the studied soil, from fine grain (CL-ML) to coarse grain (SC-SM), is in the same form without any lamination. The conformity with geotechnical conditions of the structures of the mentioned stations has been considered to simulate the soil behavior. Among the advanced models, those which have less parameters and involve simple relations, in spite of the important behavioral sides of materials, are more desirable for the geotechnical engineers. 
According to the geotechnical reports of Mashhad urban railway line $2, \mathrm{E}_{50}=10000 \mathrm{kPa}$ is for the fine grain soils of the station $A_{2}$ in the depth of $0-9 m$ and $m=0.85$ is selected. Then, regarding the shear parameters of the fine grain soil in the mentioned stations and $\sigma_{3}=100 \mathrm{MPa}$, the value of $\mathrm{E}_{50}^{\text {ref }}=10000 \mathrm{kPa}$ is calculated.

$E_{50}=80000 \mathrm{kPa}$ is for the coarse grain soil and $\mathrm{m}=0.5$ is selected. Then, given the shear parameters of the coarse grain soil in the mentioned stations and $\sigma_{3}=100 \mathrm{MPa}$, the value of $\mathrm{E}^{\mathrm{ref}}{ }_{50}=80000 \mathrm{kPa}$ is calculated.

According to $\mathrm{E}^{\mathrm{ref}}{ }_{\text {ur }}=3 \mathrm{E}^{\mathrm{ref}}{ }_{50}$ and $\mathrm{E}^{\mathrm{ref}}{ }_{50}=1.25 \mathrm{E}^{\mathrm{ref}}$ oed for the fine grain soil and $\mathrm{E}^{\mathrm{ref}}{ }_{\text {ur }}=3 \mathrm{E}^{\text {ref }}{ }_{50}$ and $\mathrm{E}^{\text {ref }}{ }_{50}=\mathrm{E}^{\text {ref }}{ }_{\text {oed }}$ for the coarse one, the limit of the input parameters of the Hardening Soil Model (HS) is as brought in Table 1.

Table 1. Specifications of the Soil Materials

\begin{tabular}{|c|c|c|c|c|}
\hline Parameter & Symbol & $\begin{array}{c}\text { The least } \\
\text { value }\end{array}$ & $\begin{array}{l}\text { The most } \\
\text { value }\end{array}$ & Unit \\
\hline $\begin{array}{l}\text { Soil behavioral } \\
\text { Model }\end{array}$ & HS & $\begin{array}{l}\text { Hardened } \\
\text { Soil }\end{array}$ & $\begin{array}{l}\text { Hardened } \\
\text { Soil }\end{array}$ & - \\
\hline Soil behavior & - & Drained & Drained & - \\
\hline $\begin{array}{l}\text { Density above water } \\
\text { table }\end{array}$ & $\gamma_{\text {sat }}$ & 13 & 18 & $\begin{array}{l}\mathrm{kN} / \\
m^{3}\end{array}$ \\
\hline $\begin{array}{l}\text { Density below } \\
\text { water table }\end{array}$ & $\gamma_{\mathrm{sat}}$ & 13 & 18 & $\begin{array}{l}\mathrm{kN} / \\
m^{3}\end{array}$ \\
\hline $\begin{array}{l}\text { Secant stiffness in } \\
\text { the standard triaxial } \\
\text { test }\end{array}$ & $E_{50}^{r e f}$ & $1.8 \times 10^{4}$ & $8 \times 10^{4}$ & $\mathrm{kN} / m^{3}$ \\
\hline $\begin{array}{l}\text { Tangential stiffness } \\
\text { for the initial } \\
\text { loading }\end{array}$ & $E_{\text {oed }}^{r e f}$ & $1.44 \times 10^{4}$ & $6.4 \times 10^{4}$ & $\mathrm{kN} / m^{2}$ \\
\hline $\begin{array}{l}\text { Stiffness of loading } \\
\text { and unloading }\end{array}$ & $E_{u r}^{r e f}$ & $5.4 \times 10^{4}$ & $24 \times 10^{4}$ & $\mathrm{kN} / m^{2}$ \\
\hline $\begin{array}{l}\text { Potential of the } \\
\text { stress level related } \\
\text { to the stiffness }\end{array}$ & $\mathrm{m}$ & 0.5 & 0.85 & - \\
\hline Effective cohesion & $C^{\prime}$ & 10 & 35 & $\mathrm{kN} / m^{2}$ \\
\hline $\begin{array}{l}\text { Effective internal } \\
\text { friction angle }\end{array}$ & $\varphi^{\prime}$ & 10 & 40 & $o$ \\
\hline Dilation angle & $\psi$ & 0 & 5 & $o$ \\
\hline $\begin{array}{l}\text { Soil-structure } \\
\text { interaction } \\
\text { coefficient }\end{array}$ & $R_{\text {int } e r}$ & 0.5 & 0.67 & - \\
\hline
\end{tabular}

\section{Method of pile and anchoring}

Along Y, the structural elements of the steel piles have been selected from the constructional profile (2IPE300). Specifications of the piles are schematically illustrated in Figure. 3. Four piles along the $\mathrm{Z}$ of models and at a distance of center to center is equal (s) to the distance between the anchor rods. Cable anchors in the failure strength of $18500 \mathrm{~kg} / \mathrm{cm}^{2}$ are used. Each cable is made of seven twisted wires and cable diameter is 0.6 inch. The excavation diameter is $116 \mathrm{~mm}$ with the angle of $10^{\circ}$ in horizontal, to perform the anchors. The length of the injection masses is $8 \mathrm{~m}$ for all anchors. The location of the anchor rods (including the distance of the first row anchor rod from surface and horizontal, and the vertical distances between the anchor rods from each other) and their lengths are according to the standard of FHWA. In this case, in all models, the distance of the first anchor rod from the surface is $1.2 \mathrm{~m}$, and the distance of the middle of the injected section of the end of the anchor rod in the first row is $4.5 \mathrm{~m}$ from the surface. Then, the free length of the first anchor rod row is $15 \mathrm{~m}$ for all models; the length of other anchor rods has been measured in terms of the first anchor rod row. There was no cover or retaining structure (Lagging or shotcrete) between spaces of the steel anchors. Tables 2 to 4 illustrate the physical specifications of the elements.

Table 2. Specifications of the steel anchors

\begin{tabular}{l|c|c|c}
\hline Parameter & Symbol & Value & Unit of Measurement \\
\hline Axial stiffness & EA & $\begin{array}{c}3.5028 \\
\times 10^{6}\end{array}$ & $\mathrm{kN} / \mathrm{m}$ \\
\hline Flexural stiffness & EI & $\begin{array}{c}6.4602 \\
\times 10^{4}\end{array}$ & $\mathrm{kN} . \mathrm{m}^{2}$ \\
\hline Weight & $\mathrm{W}$ & 0.828 & $\mathrm{kN} / \mathrm{m}$ \\
\hline Poison's ratio & $v$ & 0.3 & --- \\
\hline Material behavior & \multicolumn{3}{|c}{ Elastic } \\
\hline Element & \multicolumn{3}{|c}{ Plate } \\
\hline
\end{tabular}

Table 3. Specifications of the injected mass

\begin{tabular}{l|c|c|c}
\hline Parameter & Symbol & Value & Unit of Measurement \\
\hline Axial stiffness & EA & $\begin{array}{c}5.28 \mathrm{x} \\
10^{4}\end{array}$ & $\mathrm{kN} / \mathrm{m}$ \\
\hline Element & \multicolumn{4}{|c}{ Geogrid } \\
\hline
\end{tabular}

Table 4. Specifications of the steel anchors

\begin{tabular}{l|c|c|c}
\hline Parameter & Symbol & Value & Unit of Measurement \\
\hline Axial stiffness & EA & $\begin{array}{l}1.149 \\
\times 10^{5}\end{array}$ & $\mathrm{kN}$ \\
\hline Material behavior & \multicolumn{2}{|c}{ Elastic } \\
\hline Element & \multicolumn{3}{|c}{ Node to node anchor } \\
\hline Pre-stress Force & \multicolumn{2}{|c}{$200 \mathrm{kN}$} \\
\hline
\end{tabular}

Figure 4 illustrates the first phase of the construction stages. In this stage, the shafts are excavated for steel piles and these piles are interred in these shafts. In all models, the depth of the interred pile is $3 \mathrm{~m}$. 

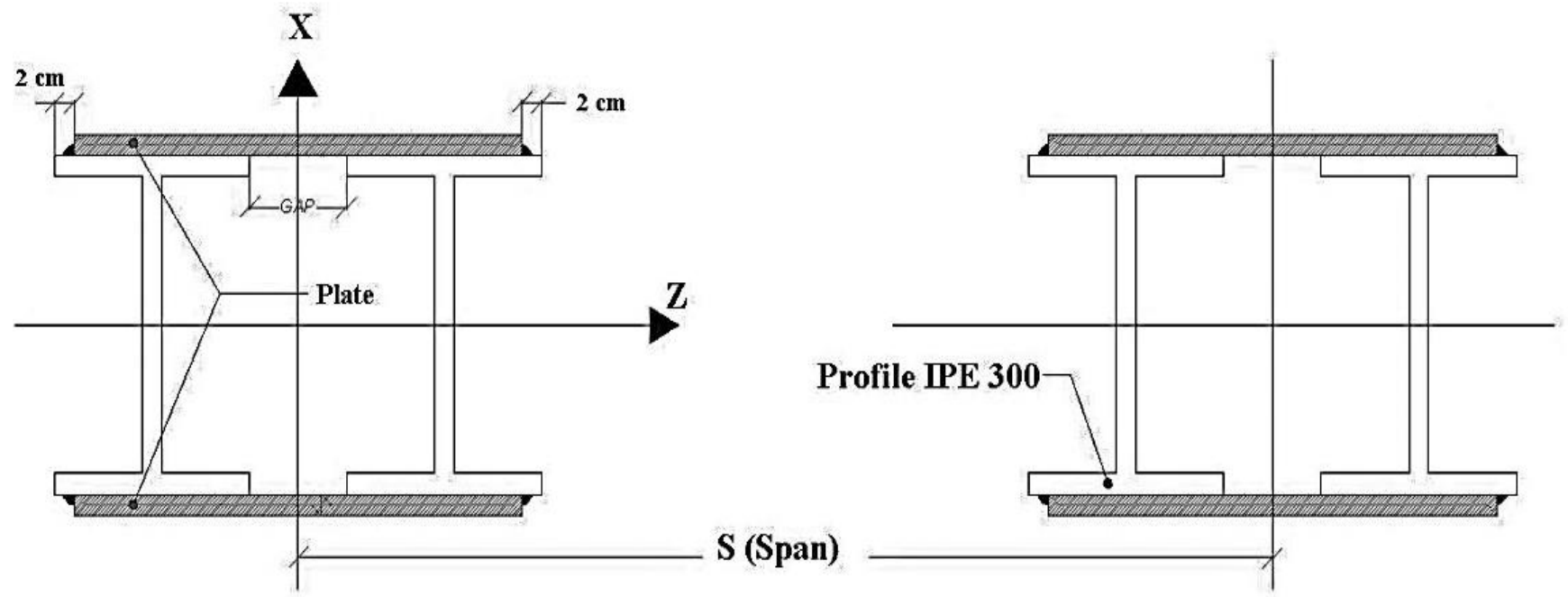

Figure 3. Schematic view of the profiles 2IPE300

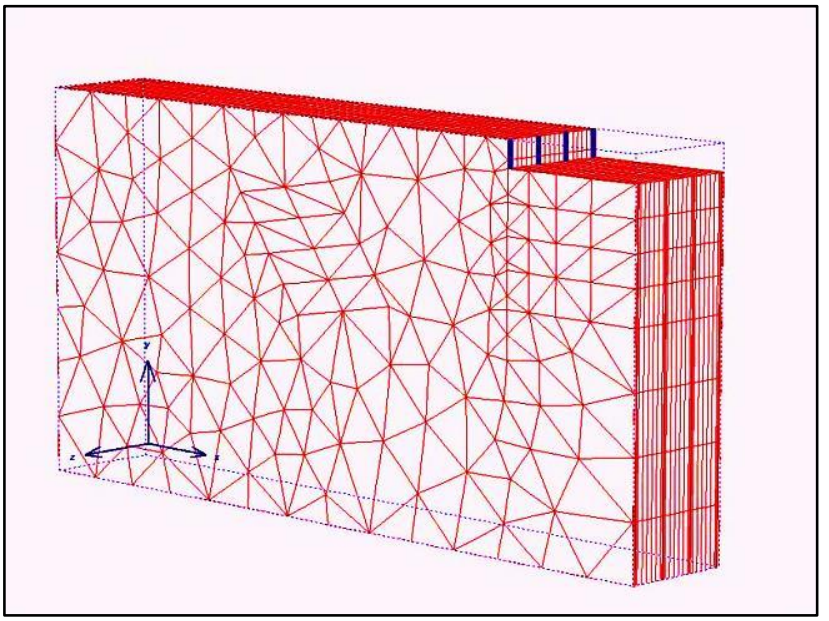

Figure 4. Perspective of the phase 1 of the model in stage construction analysis

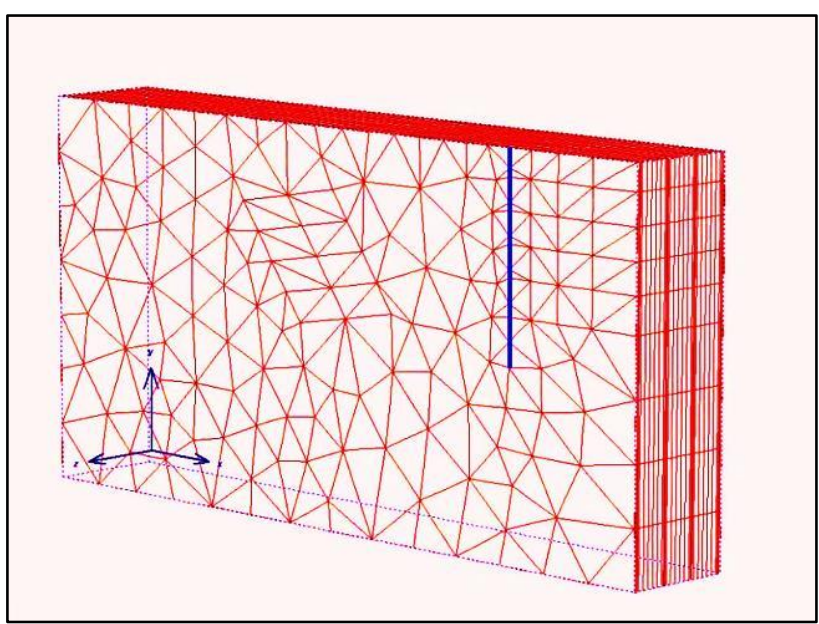

Figure 5. Perspective of the phase 2 of the model, excavation in the depth of $1.7 \mathrm{~m}$

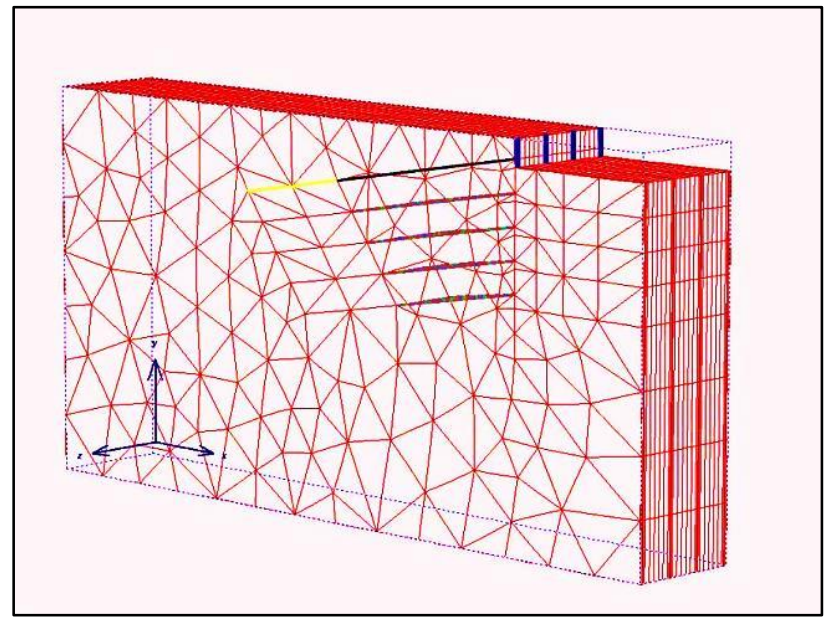

Figure 6. Perspective of the phase 3 of the model activating the first row of anchors

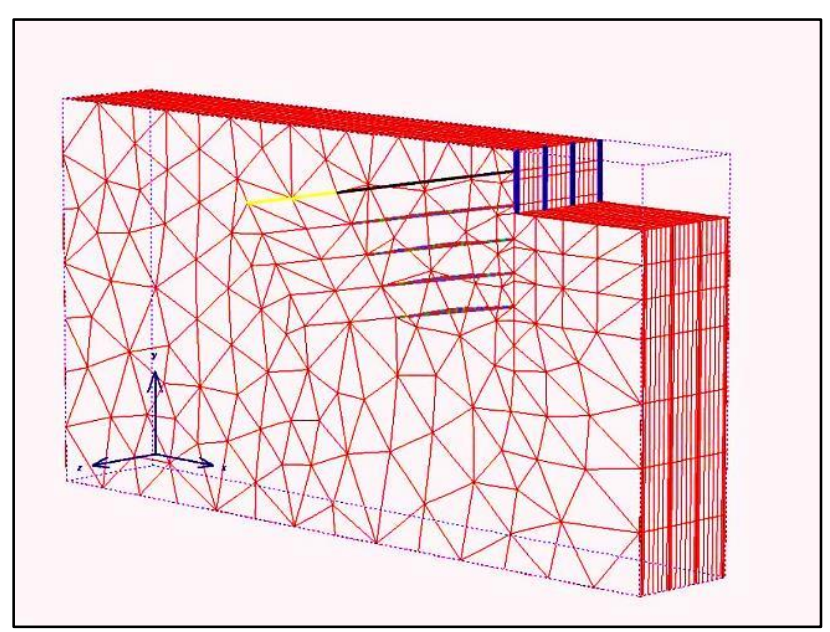

Figure 7. Perspective of the phase 4 of the model - the second stage of excavation 


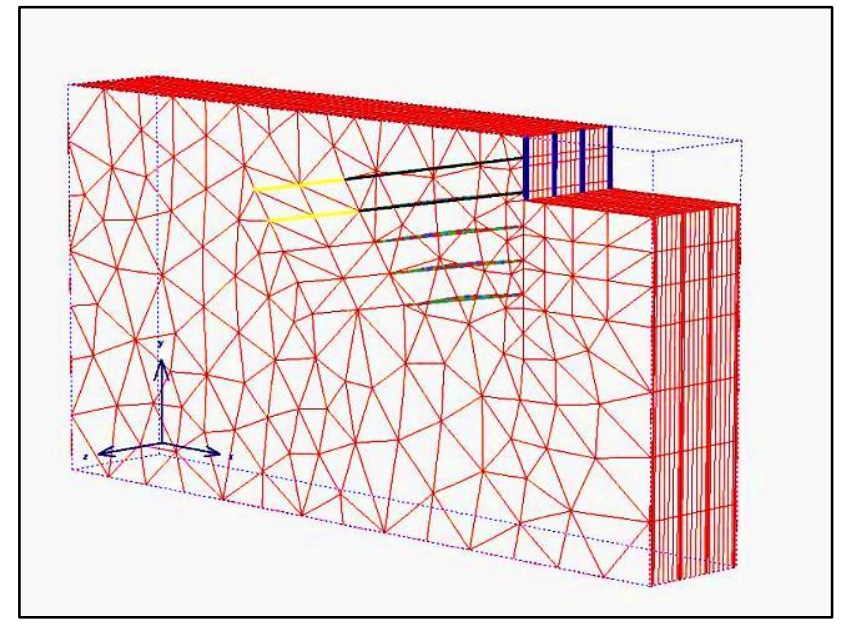

Figure 8. Perspective of the phase 5 of model - activating the second row of anchors

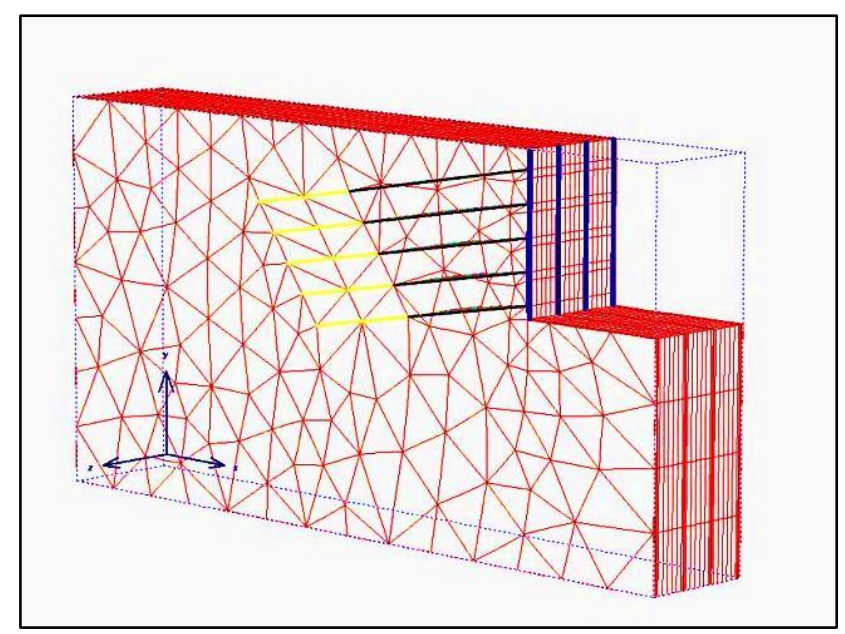

Figure 9. The final phase of excavation

Figure 5 illustrates the second phase. At the beginning of this phase, the stress effect resulting from excavating piles has been omitted and the change of the first places as a result of stress will be zero. Then, the excavation will be performed to the level $0.5 \mathrm{~m}$, which is lower than that of the first anchor rod row (in depth of 1.2). In this phase, the steel piles are active, while the steel anchors are not. Figure 6. illustrates the third phase that includes the prestress force on the steel anchors. The three first phases are the same for all models; however, after that (phase 4), the depth of excavation will be changed based on the change of the vertical distances between anchors in different models. In the phase 4 , excavation is performed to the expected level. In this phase, the steel piles and the first row of anchors are used. For example, the vertical and horizontal distance is $2 \mathrm{~m}$ (Figure 7). In the phase 5, the pre-stress force of the second anchor rod row is used (Figure 8). All of the stages will be repeated to reach the final level of excavation, the depth of $10 \mathrm{~m}$, based on the distances of the anchors (Figure 9).

\section{RESULTS AND DISCUSSION}

\section{Study of soil anchoring parameters}

Anchoring zone can be found with displacement counters in the soil movement direction, in addition to the rotation of the directions of the principal stress. The displacement contours in the direction $x$ have been illustrated in Figures 10-15 to study, this case, the horizontal sections in $\mathrm{x}-\mathrm{z}$. At first, the relation between the safety factor and arching has been illustrated for quantification. After that, the parameters effective on the safety factor will be considered. As represented in figures $10-15$, the safety factors are 1.1, 1.7, 2.5, 3.0, 3.6 and 3.9, respectively.

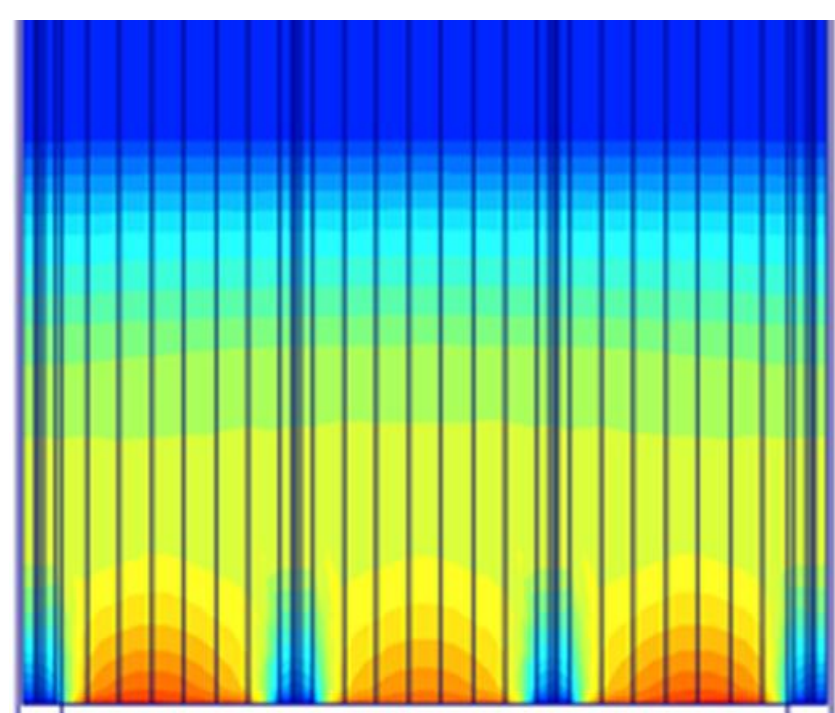

Figure 10. The circular pattern of the lateral displacement of soil (Ux) between piles with the safety factor of 1.1

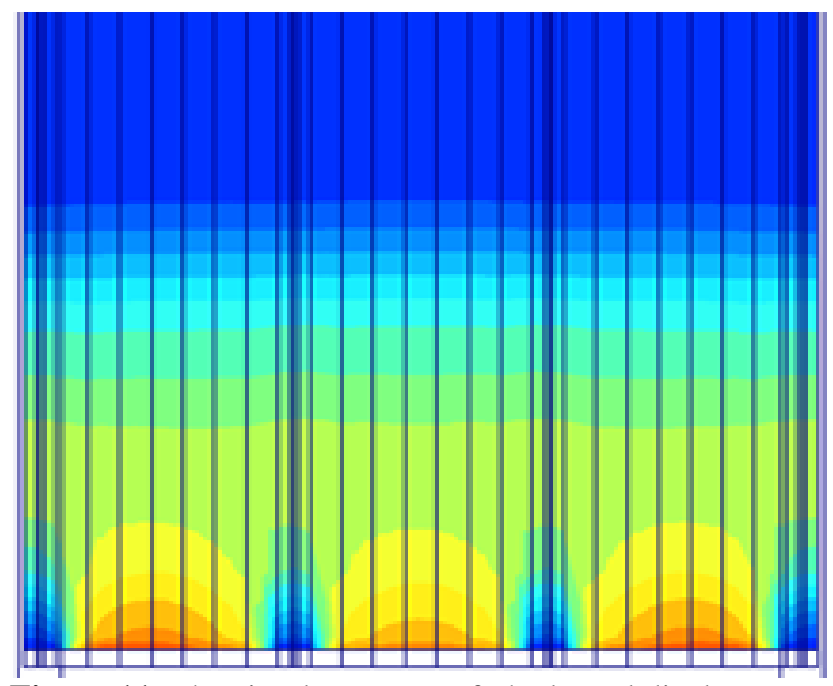

Figure 11. The circular pattern of the lateral displacement of soil (Ux) between piles with the safety factor of 1.7 


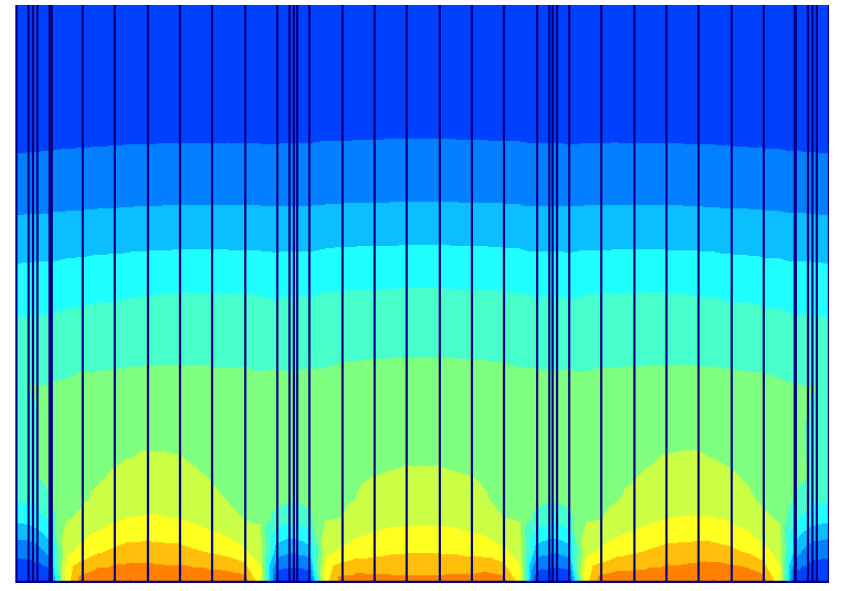

Figure. 12. The circular pattern of the lateral displacement of soil ( $\mathrm{Ux}$ ) between piles with the safety factor of 2.5

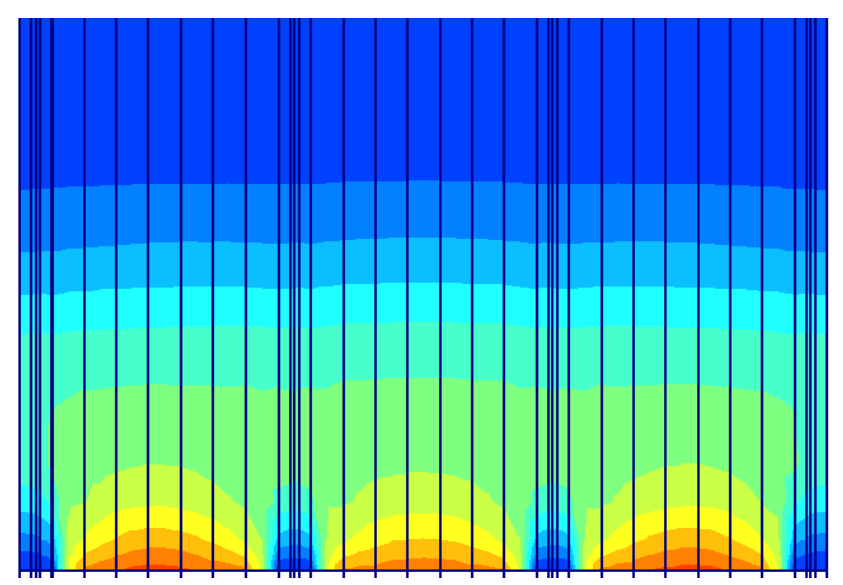

Figure. 13. The circular pattern of the lateral displacement of soil (Ux) between piles with the safety factor of 3.0

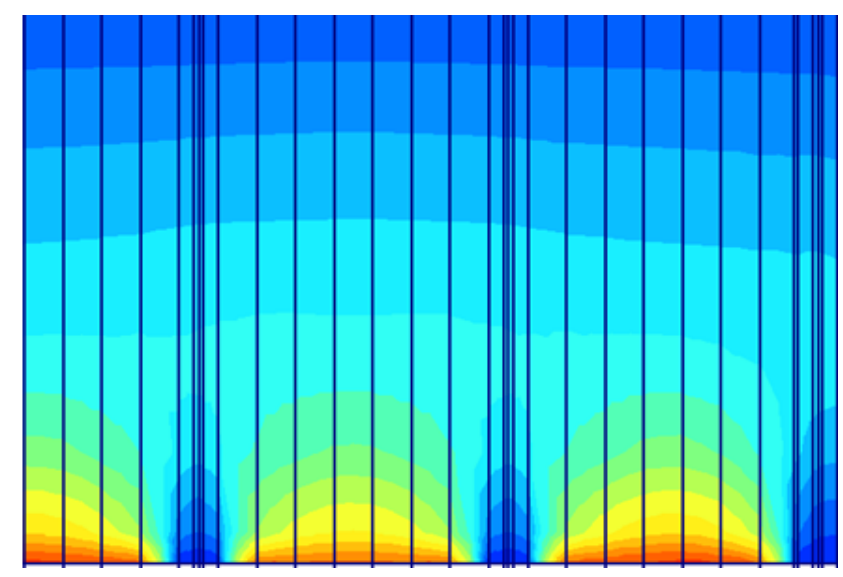

Figure. 14. The circular pattern of the lateral displacement of soil (Ux) between piles with the safety factor of 3.6

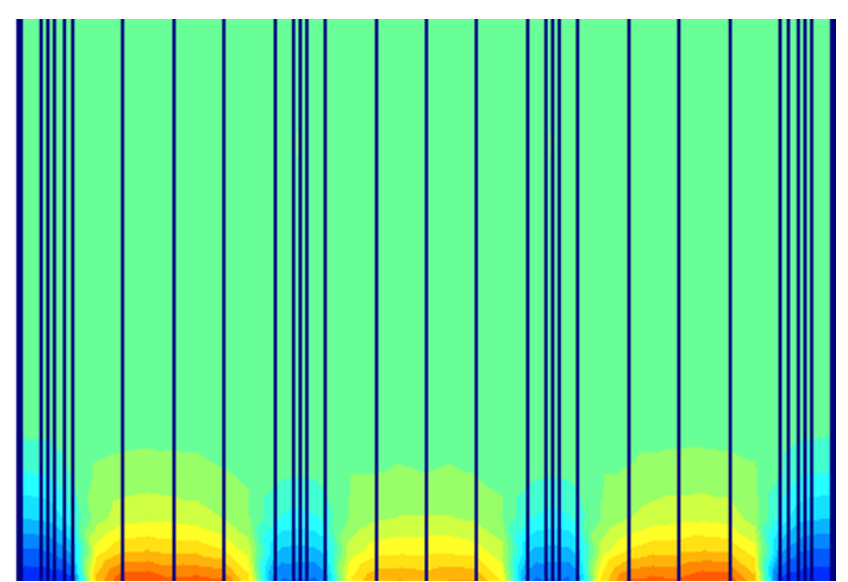

Figure 15. The circular pattern of the lateral displacement of soil (Ux) between piles with the safety factor of 3.9

In Figures 9-18, the darker sections illustrate more displacement, while the lighter ones represent the less displacement. As shown, the deformation pattern of soil in the direction $\mathrm{x}$ is in the arch form between the piles. The height and width of these arches are different; the reason is that with a higher safety factor, the height and width of these arches will be decreased. The reason for this displacement between pile and block as a result of arching can be explained. This is because transferring the soil pressure to the piles and blocks supporting in the arching directions will occur. In other words, the transfer of stress to the piles and anchors will be increased, while the displacement will be decreased as a result of the arching phenomenon.

\section{Box-Cox method}

When the relation between error and average is not clear as that in the logarithmic and square transformations, then a potential transformation can be used. Box-Cox transformation function is a nonlinear monotonic transformation including log-linear and some special linear functions (Fitzenberger et al., 2005). It is an important transformation covering many distribution functions. Hence, this linear transformation can transform to normal distribution. The general form of this transformation is as follows (3):

$$
z=\left\{\begin{array}{l}
\frac{x^{\lambda}-1}{\lambda}(\lambda \neq 0), x>0 \\
\ln (x)(\lambda=0), x>0
\end{array}\right.
$$

Where, $x$ is the data that should be normalized, $\lambda$ is a real value and $Z$ is a transformed value. If this transformation does not give the data to the normal distribution, the minimum data will be ordered. Also, the reverse transformation of this function is simple, and this 
is one of the advantages of this method. In this case, the distribution function of data is as follows (4):

$$
f(x)=\frac{1}{\beta \sqrt{2 \pi}} e^{-\frac{1}{2}\left[\frac{x^{\lambda}}{\beta}-\alpha\right]}
$$

Where,

$\alpha$ and $\beta$ refer to the average and standard deviation of the transformed data, respectively. Definitions of average $(x)$ and skewness (s) should be used to calculate the real average and variance $(5,6)$.

$$
\begin{gathered}
\bar{x}=E(X)=\int_{\varepsilon}^{\infty} X f(X) d x \\
s=E(x-\bar{x})^{2}=\int_{\varepsilon}^{\infty}(x-\bar{x})^{2} f(x) d x
\end{gathered}
$$

\section{Method of estimating $\lambda$}

\section{Using standard curves to calculate $\lambda$}

As shown in Figures 16 and 17, the data related to the normal distribution have not been covered completely; so, the distribution of the safety factor is normal if $\lambda=0.06$. This method has also been used for four independent input variables. $\lambda$ values of the variables are illustrated in Table 5.
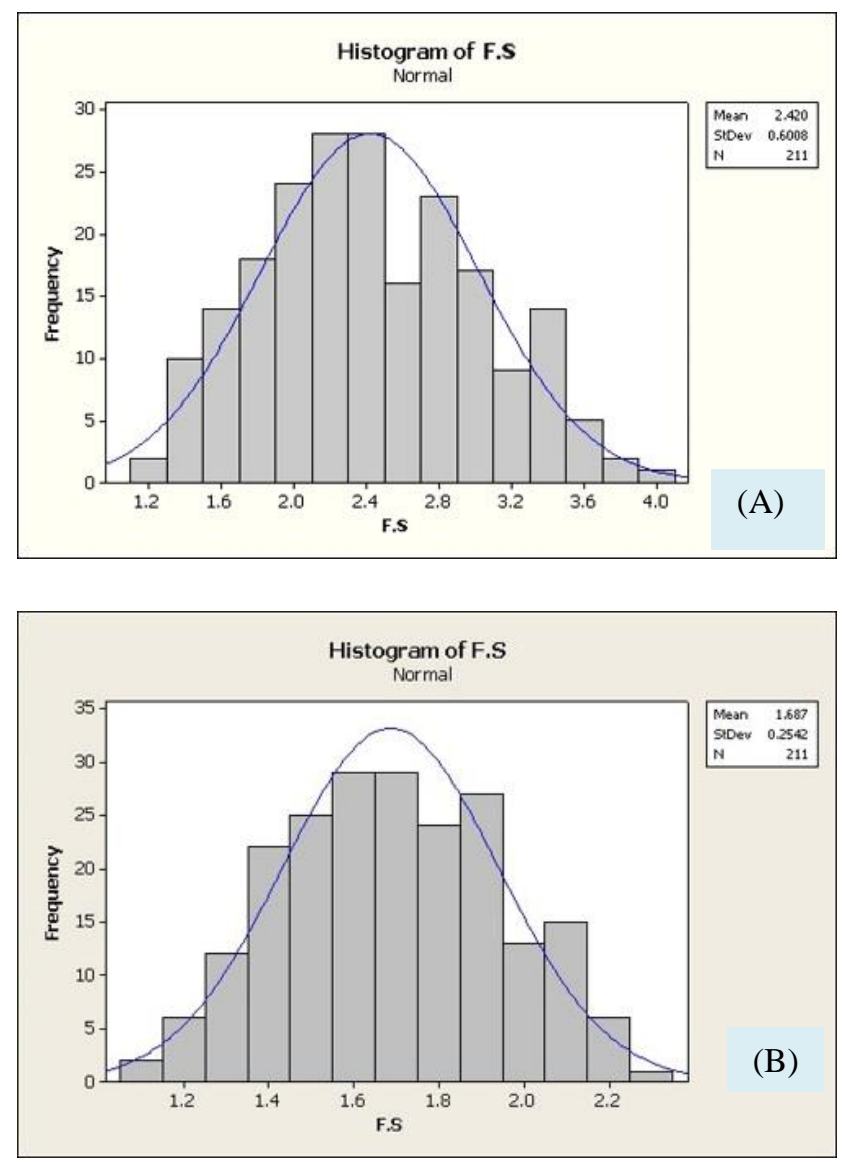

Figure 16. (A) Histogram of the safety factor distribution with raw data; (B) Histogram of the safety factor distribution after using the Box- Cox transformation

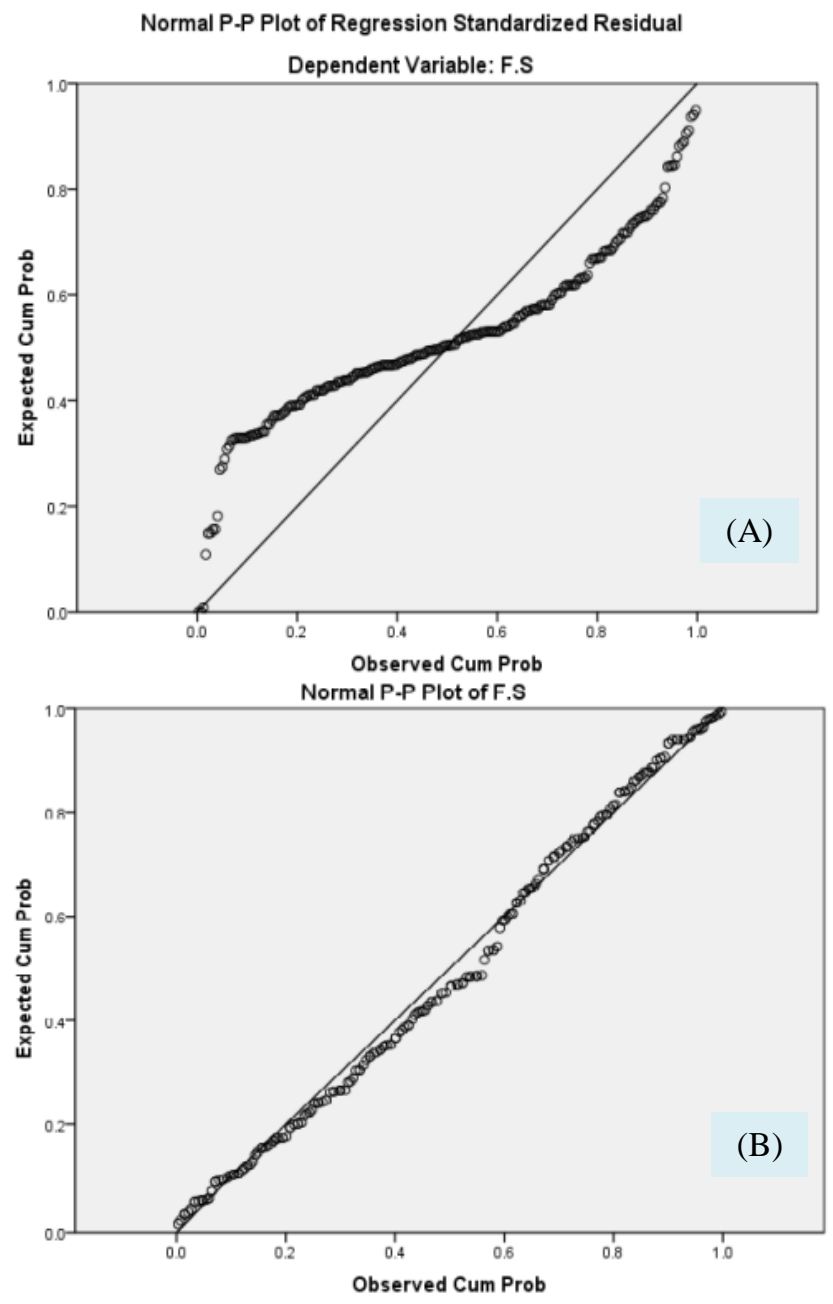

(A)

(B)

Figure 17. (A) Cumulative distribution of the safety factor with the raw data; (B) Cumulative distribution of the safety factor after using the Box- Cox transformation

Table 5. $\lambda$ Values for the dependent and independent variables

\begin{tabular}{lc}
\hline Variable & $\boldsymbol{\lambda}$ \\
\hline The distance between anchor rods & 2.88 \\
The internal friction angle & -0.65 \\
Cohesion & 2.6 \\
Soil density & 5 \\
Safety factor & 0.06 \\
\hline
\end{tabular}

\section{Selecting the best regression model}

As there are few input variables, using all possible regression methods is preferred over other strategies for selecting the variable. Using this method seems to be logical. Then, in the first step, all possible regression methods $\left(2^{5}-1\right)$ are processed by the mentioned method; after that, the processed patterns are divided to a set 
composed of 1-5 variables. Then, the patterns will be selected according to some criteria such as the coefficient of determination, the coefficient of determination adjusted, Mean Square Error (MSE), Mallow's $C_{p}$ and the best model used by the five mean variables. (Table. 6)

As represented in Table 6, the processed models includes cohesion; the second model includes cohesion and the internal friction angle. The three-variable model includes cohesion, internal friction angle and soil density; the fourth model consists of cohesion, internal friction angle, soil density and the distance between anchor rods. Finally, the fifth model covers cohesion, internal friction angle, soil density, the distance between anchor rods and the elastic modulus of soil.

Table 6. Summary of the results obtained from all possible regression models

\begin{tabular}{lcccc}
\hline $\begin{array}{l}\text { Number of } \\
\text { Variables }\end{array}$ & MSE & $\mathbf{R}^{\mathbf{2}}$ & Adjusted $\mathbf{R}^{\mathbf{2}}$ & Mallow 'sCp \\
\hline 1 & 0.133 & 0.637 & 0.635 & -0.45 \\
2 & 0.710 & 0.808 & 0.806 & -0.16 \\
3 & 0.040 & 0.892 & 0.890 & 1.025 \\
4 & 0.022 & 0.939 & 0.938 & 5.6 \\
5 & 0.023 & 0.939 & 0.938 & 0.34 \\
\hline
\end{tabular}

\section{Standardized regression coefficients}

It is difficult to compare the regression coefficients, because $\beta_{\mathrm{j}}$ (dependent variables coefficients) is a reflex of the measurement units of the independent variable $X_{j}$. It will be useful to use the scaled dependent and independent variables that can lead to the regression coefficients without unit. There are currently two scaling methods. The first one is unit normal scaling. The second one is unit length scaling. Then, the effect of each independent variables can be addressed by the standardized regression coefficients (Figure 18).

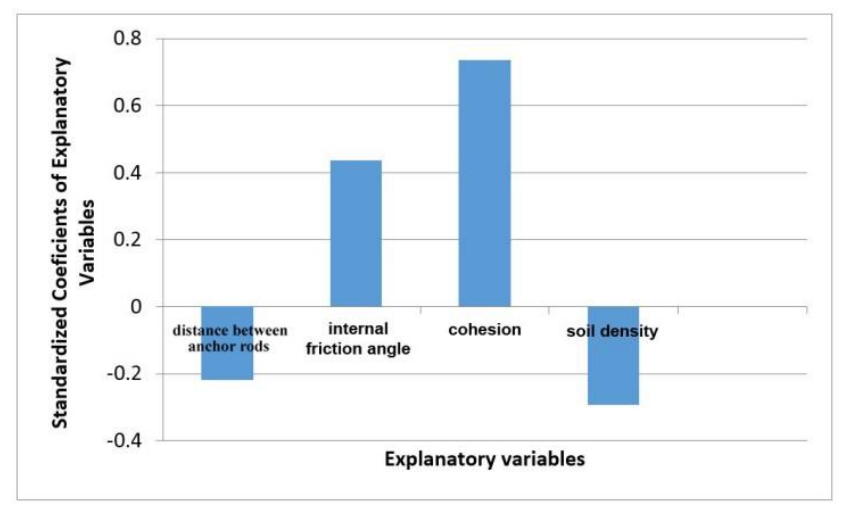

Figure 18. The standardized regression coefficients for the regression model with 4 variables
As shown, cohesion and internal friction angle have the most positive effect on the safety factor; , while soil density and the distance between anchor rods have a negative effect. These cases were expected.

\section{The results obtained from neural networks}

The neural network has been considered to expect the safety factor. It is supposed that there is a nonlinear and complex relation between the safety factor and the specifications of soil. Consequently, the neural network has been considered to study the correlation between the safety factor and the model parameters and to compare the results obtained from multiple regression analysis.

\section{Preprocessing the data}

Training of the neural network can be more effective if some targets and inputs are preprocessed. Error estimation method is used to scale the inputs whose value of error is equal to zero. Then, the inputs and target will be normal.

Making model by back propagation networks to estimate the safety factor

In this research, to estimate the safety factor, a leading network with a back propagation algorithm and error was used. To train the network, the data were divided randomly in three classes including training, validation and test. Then, $70 \%, 15 \%$ and $15 \%$ of the data were divided for training, validation and test, respectively.

Levenberg-Marquardt algorithm was used to train the network and the root-mean-squared error was also applied as a cost function. The network was composed of two hidden layers and one output layer with arrangement (1, 50, and 20); the tangent sigmoid function was in the hidden layers and linear function was in the output layer (Figure.19). The number of the optimized layers and neurons was obtained based on the trial and error; then the desirable network was not unique. The results obtained from three subsets of training, validation and test have been illustrated in Figure 20. The correlation coefficient between the measured and expected values was 0.998, 0.993 and 0.994 for training (Figure $20 \mathrm{~A}$ ), validation (Figure $20 \mathrm{~B}$ ) and test (Figure $20 \mathrm{C}$ ), respectively.

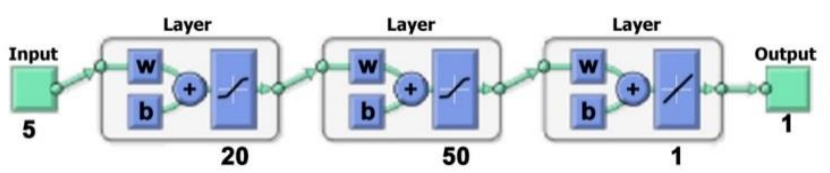

Figure 19. Schematic network including two hidden layers and one output layer 


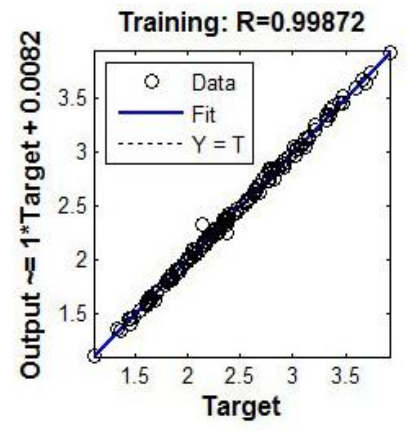

(A)

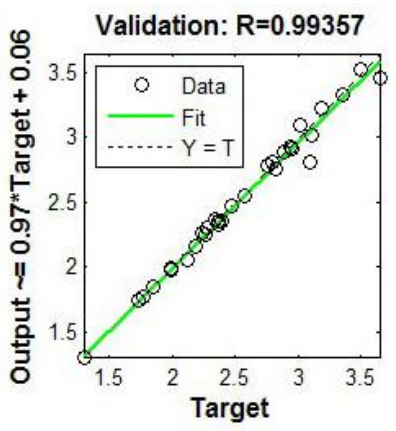

(B)

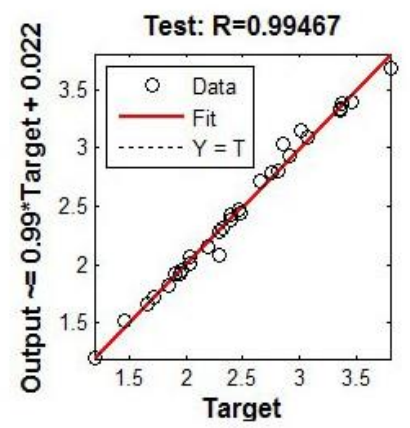

(C)

Figure 20. Correlation coefficients for training, validation and test

Square error curve based on the training cycles has been illustrated in Figure 21. The error values of validation and test were very close to each other; so, the result was good, and preprocessing would not occur.

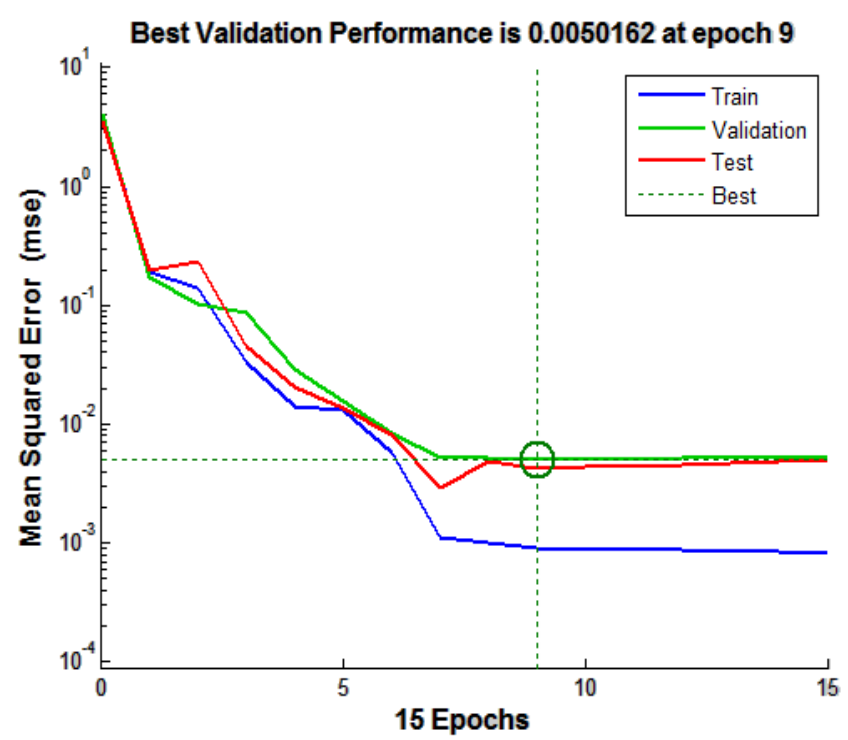

Figure 21. Square error curve based on the training cycles for training, validation and test

\section{Analyzing post-training}

Training network efficiency is measured by using the errors of training, test and validation sets; however, it is better to study the details of the net reaction carefully. Postreg method has been designed to implement the analyses. So, the following instructions can illustrate how regression analyses can be done in the training network.

$\mathrm{a}=\operatorname{sim}($ net,p);

$[\mathrm{m}, \mathrm{b}, \mathrm{r}]=\operatorname{postreg}(\mathrm{a}, \mathrm{t})$

$\mathrm{m}=0.8879 \quad \mathrm{~b}=-0.1429 \quad \mathrm{r}=0.9770$

where $m$ and $b$ refer to the slope and linear fit and $y$ is the best regression linear related to the outputs. If there is a perfect fit (that is the outputs are equal to the target completely), the slope will be equal to 1 . As found in this research, the result was very close to the desirable values. The correlation coefficient was 0.9770, which was increased in comparison with the regression results. The graphic output has been illustrated in Figure 22.

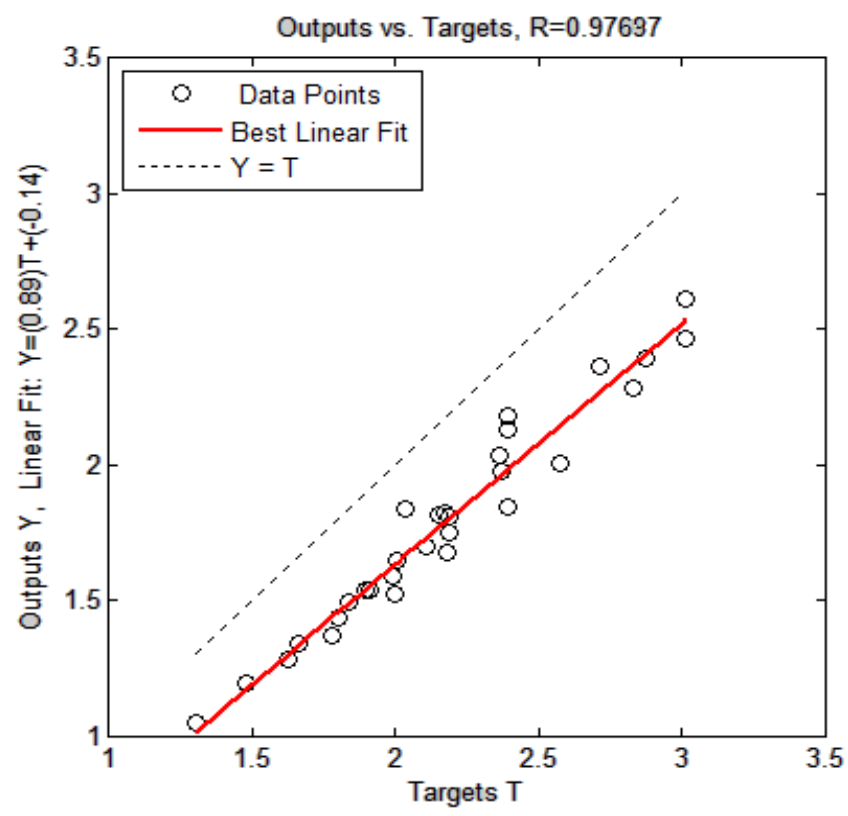

Figure 22. The linear correlation between the measured and expected values after post training

\section{CONCLUSION}

In this research, we tried to provide a useful relation by using multiple regression and neural network so that it would the ordinary methods; it could serve as a fast and simple solution for the engineers and employers to solve problems. By conducting the initial studies and finding the geotechnical parameters of soil, different models with effective parameters were made by PLAXIS 3D TUNNEL. 
As the time of response was very long, the safety factor curve opposite of this parameter was drawn coincidently with making these models to omit the ineffective parameters and save the time. Totally, 212 models were made on the basis of the available possibilities. 5 parameters were measured on 212 models and they were made by the data. Then, various models with various variables were processed by using multiple linear regression. The best model was obtained by using all regression models method. In this study, although data was not normal, since the result of parametric regression was desirable, nonparametric methods such as nonparametric regression could not be used.

It should be , however, noted that multiple regression analysis and artificial neural network training are used to expect the parameter which is the safety factor; so, they cannot be useful tools to analyze the effect of each independent variable on the dependent parameter. To summarize:

1. There is a direct relation between safety factor and arching; as arching is increased by enhancing the safety factor (displacement will be decreased), then the safety factor can considered to reach a quantity concept and a relation.

2. Soil cohesion (c) has the most positive effect on the safety factor.

3. Internal friction angle $(\varphi)$ of the soil after cohesion plays the most important role in determining the stability of the excavation.

4. Soil density $(\gamma)$ is the first effective parameter on the safety factor and anchoring has an inverse relation; so, if soil density is increased, the safety factor will be decreased.

5. The distance between anchor rods (sh) is the next parameter. Although it has less effect in comparison to the mentioned parameters, it is an important parameter as there is a reverse relation between it and the safety factor; so, when this parameter is increased, the safety factor will be decreased.

6. The correlation coefficient as a result of the neural network was 0.994 for the subset of test. This was more than that of multiple regression, thus indicating that the neural network can be very strong in determining the relations between $\mathrm{t}$ variables.

\section{DECLARATIONS}

\section{Author's contribution}

All authors contributed equally to this work.

\section{Competing interests}

The authors declare that they has no competing interests.

\section{REFERENCES}

ASCE (1958). Glossary of Terms and Definition in Soil Mechanics, Soil Mechanics and Foundations Division, 84: $1-43$.

Chen L and Poulos H (1997). Piles Subjected to lateral soil movments. Journa of eotechnical and Geoenviromental Engineering, $\quad$ ASCE, 123(9): 802-811. https://doi.org/10.1061/(ASCE)1090-0241(1997)123:9(802) ; Google Scholar

Fattah MY, Sabar BS, Hassan HA (2015). Soil arching analysis in embankments on soft clays reinforced by stone columns. Structural Engineering and Mechanics, 56(4): 507-534. Google Scholar

Fitzenberger B, Wilke RA and Zhang X, (2005). A Note on Implementing Box-Cox Quantile Regression. ZEW - Centre for European Economic Research Discussion Paper No. 04061, Available at SSRN: https://ssrn.com/abstract=604441 or Google Scholar ; http://dx.doi.org/10.2139/ssrn.604441

Hagan MT, Demuth HB, Beale MH (1997). Neural network design PWS Publishing. Boston, MA. Google Scholar

Kahyaoglu Y (2009). Computational 3D finite element analyses model passive piles. Computational Materials Science, 46(1):193-202. Google Scholar ; https://doi.org/10.1016/j.commatsci.2009.02.022

Khosravi MH, Bahaaddini M, Kargar AR, Pipatpongsa T (2018) Soil arching behind retaining walls under active translation mode: review and new insights, 52(2): 131-140. Google $\underline{\text { Scholar }}$ https://dx.doi.org/10.22059/ijmge.2018.264011.594754

Kourkoulis R, Gelagoti F, Anastasopoulos I (2011). Slope stabilizing piles and pile groups:parametric study and design insights, Journal of Geotechnical and Geoenviromental Engineering, 137(7):663-677. https://doi.org/10.1061/(ASCE)GT.1943-5606.0000479 ; Google Scholar

Lai HJ, Zheng JJ, Cui MJ, Chu J. (2020). "Soil arching” for piled embankments: insights from stress redistribution behaviour of DEM modelling. Acta Geotechnica. 2:1-20. Google

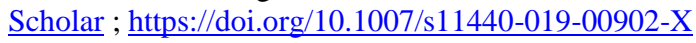

Plaxis 3D Tunnel Software (2004). User ' manual, Version 2, Delfet University of Technology, Netherlands.

Qiu-chang L, Jian-wei Z. (2010). Numerical analysis of soil arching effects of anti-sliding pile. In 2010 International Conference on Computer Application and System Modeling (ICCASM 2010). Google Scholar ; http://dx.doi.org/10.1109\%2FICCASM.2010.5620129

Vermeer P, Punlor A, Ruse N (2001). Arching effects behind a soldier pile wall, Computer and Geotechnics, 28, 379-396.

Vermeer PA, Punlor A, Ruse N (2001). Arching effects behind a soldier pile wall. Computers and geotechnics. 28(6-7): 37996. https://doi.org/10.1016/S0266-352X(01)00010-6 ; Google Scholar 
Wang W, Yen B. (1974). Soil arching in slopes, Journal of Geotechnical Engineering, 100(1):61-79. Google Scholar ; http://worldcat.org/issn/07339410

Wu J, Li C, Liu Q, Fan F (2017). Optimal isosceles trapezoid cross section of laterally loaded piles based on friction soil arching. KSCE Journal of Civil Engineering. 21(7): 26552664. Google Scholar ; https://doi.org/10.1007/s12205-017$\underline{1311-5}$ 